\title{
Geotechnical verification of impact compaction
}

\author{
P. J. Waddell ${ }^{1}$, R. A. Moyle ${ }^{2}$ \& R. J. Whiteley ${ }^{1}$ \\ ${ }^{1}$ Coffey Geotechnics, Sydney, Australia \\ ${ }^{2}$ Coffey Geotechnics, Harrogate, UK
}

\begin{abstract}
Remediation of brownfield sites is often dominated by environmental treatment of the fill. However, conventional methods for geotechnical verification of ground improvement techniques are invasive, slow, costly and of limited accuracy. Seeking improvements to this process, we applied both innovative geophysical testing and conventional testing methods to assess ground improvement in a full scale impact compaction trial. Ground improvement using an impact roller was proposed to form a compacted soil raft suitable to support commercial development, thus avoiding excavation and compaction of the full fill thickness.

A range of geotechnical testing and monitoring techniques were utilised to assess the effect of the impact compaction, including: Multi-channel Analysis of Surface Waves (MASW), Electric Friction Cone Penetrometer Tests (CPT), In situ Density Tests, Dynamic Cone Penetration Tests, and Topographic survey.

The results of extensive geotechnical and geophysical testing showed reasonable correlation between the CPT, density and S-wave velocity results. These tests showed a similar depth of influence as a result of impact compaction, which generally increased with increasing number of passes.

The MASW testing provided shear wave velocity profiles showing the consistency achieved in the landform. A statistical approach was used to develop a relationship between the MASW testing and DDR. This allowed a target shear wave velocity to be identified and the MASW to be used as a rapid means to assess both density and variability within the fill before and after ground treatment.
\end{abstract}

Keywords: density, compaction control, MASW, impact rolling. 


\section{Introduction}

A trial site on vacant land was selected that formed part of a large proposed commercial and industrial redevelopment in the western suburbs of Sydney Australia. Initial geotechnical investigations indicated a significant thickness of fill but there were only limited historical records describing the nature and level of compaction of this fill. It is probable that the bulk of the fill originated from crushed shale and sandstone excavated locally during a large rock construction in the 1920's.

The subsurface profile at the trial site typically comprised gravelly clay fill derived from shale rock up to $5.5 \mathrm{~m}$ thick, overlying residual soil and interstratified shale and sandstone bedrock. In situ testing indicated that the fill was relatively dense, with typical in situ densities exceeding $2 \mathrm{t} / \mathrm{m}^{3}$; however, recorded density variations were between $+32 \%$ and $-18 \%$. Our assessment was that even though the fill had been in place for a considerable period, it could not be considered "Controlled Fill" and could not be relied upon to provide the required uniform settlement characteristics for the commercial floor slabs and industrial pavements that were planned for this site.

From the various ground treatment techniques that were considered impact rolling was identified as a cost-effective means of forming a compacted soil raft suitable for the development. In order to confirm the effectiveness of impact rolling a full scale trial was undertaken.

\section{Ground improvement trial}

\subsection{Ground improvement trial strategy}

The specification for the full scale trial that was undertaken on the site required an assessment of the following:

- The suitability of impact compaction at the site, under the following criteria:

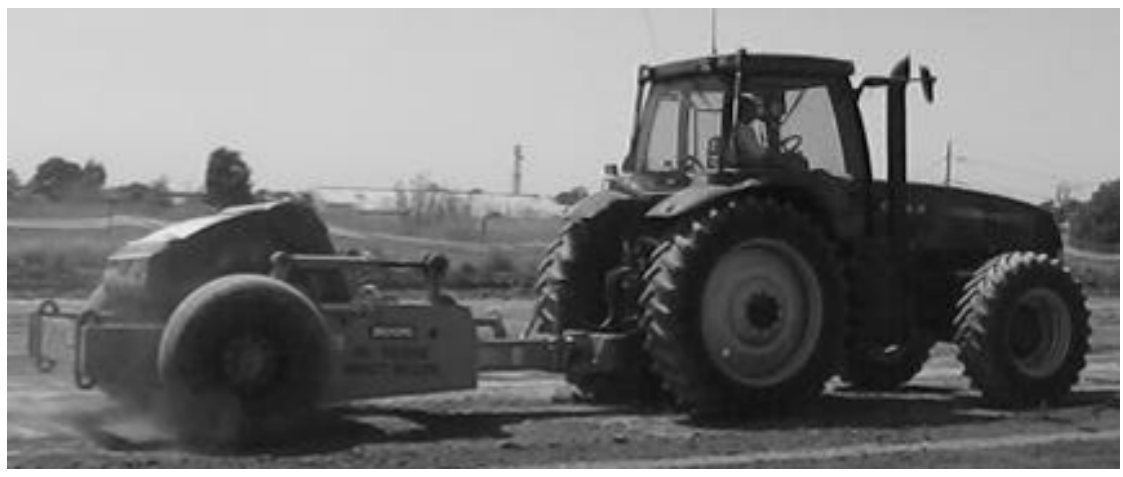

Figure 1: $\quad$ Towed 12t impact roller. 
(i) Uniformity, in terms of density, of the treated landform

(ii) Achieve at least $98 \%$ of the Standard Maximum Dry Density (SMDD) in the upper $1.5 \mathrm{~m}$ of the landform.

- The required weight of the roller and the number of passes with the roller to achieve the above criteria.

Based on the trial a geotechnical verification strategy was to be developed to assess compliance with the above criteria for the larger site area.

The impact compaction trial was carried out using 8-tonne and 12-tonne square rollers (Figure 1) on separate parts of the trial area. These two parts were further subdivided into 4 sub-areas, in which a different number of machine passes were adopted up to a maximum of 40 passes.

\subsection{Electromagnetic screening}

As this was a brownfield site electromagnetic (EM) screening was undertaken prior to the commencement of the trial to examine electrical conductivity variations to approximately $5 \mathrm{~m}$ depth to assess whether there were obstruction within the fill. EM screening is often used for rapid subsurface screening of such sites, whereby variations in electrical conductivity can be correlated to buried metallic materials, lateral variations within the fill and the electrical contrast between the fill and natural ground.

A Geonics EM31 MK2 conductivity meter with automatic DGPS positioning and a nominal line spacing of $5 \mathrm{~m}$ was used to measure the induced electromagnetic response of the site. The results of the EM31 screening of the trial area are plotted as a contour plan of apparent conductivity in Figure 2. A number of major EM anomalies were identified representing buried highly

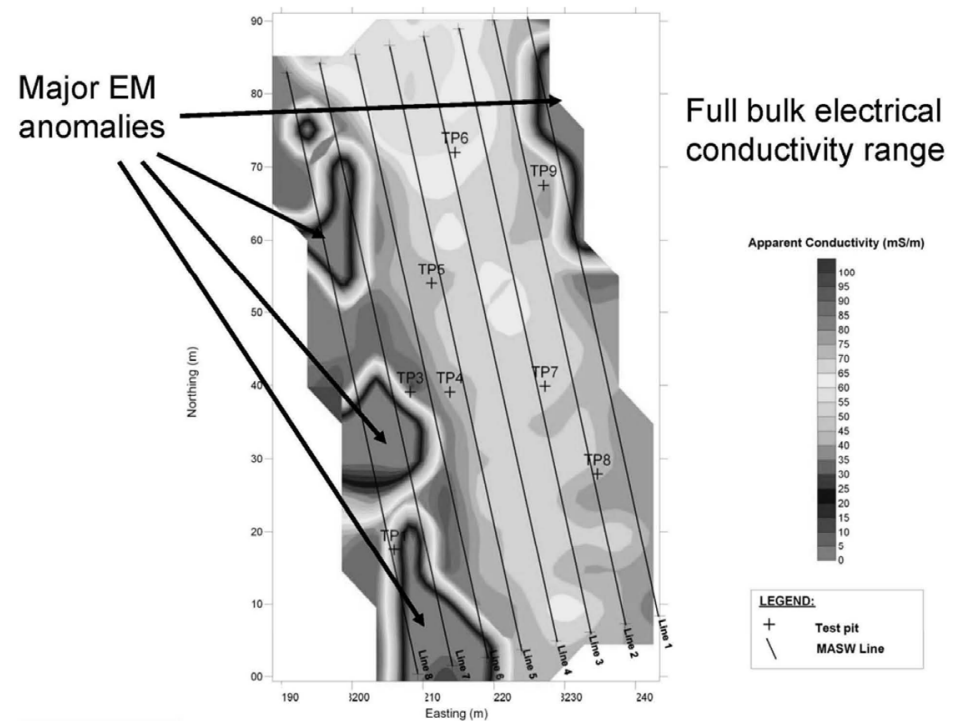

Figure 2: $\quad$ Electromagnetic survey results. 
conductive objects within the trial area (Figure 2). These anomalies consisted of low apparent conductivity values, which are typically obtained when large quantities of metal are present in fill due to strong attenuation of the secondary magnetic field.

During the course of the trial works, these anomalous areas were excavated and revealed steel reinforced concrete slabs buried within the upper $1 \mathrm{~m}$ of fill. The slabs were removed prior to the compactions trials.

\subsection{Pre- and post-compaction geotechnical testing}

Geotechnical investigations to facilitate assessment of the effectiveness of the impact compaction were carried out pre and post-compaction as follows:

- $\quad$ MASW geophysical testing along 8 parallel lines;

- CPT probes at 40 locations pre-compaction and 39 locations postcompaction to depth varying between $2 \mathrm{~m}$ and $10 \mathrm{~m}$;

- $\quad$ Test pits at 8 locations, excavated to $3 \mathrm{~m}$ depth, with nuclear tests every $0.3 \mathrm{~m}$; and

- Dynamic Cone Penetrometer (DCP) Testing adjacent to each test pit to depths up to $3 \mathrm{~m}$.

Typically the post compaction MASW testing and CPT probes were carried out within $1 \mathrm{~m}$ of the pre-compaction testing. Due to the size of the test pits, the centre of the post-compaction test pits were generally located within $5 \mathrm{~m}$ of the centre of the pre-compaction test pits.

Topographic survey was also undertaken before and during the impact roller trial to monitor 'global' settlement trends within the fill.

\subsection{MASW testing methodology}

Seismic surface wave testing of Rayleigh waves using multi-channel seismographs and linear surface array of detectors is an improved method for obtaining in situ shear (S) wave velocities of the earth. The MASW method enables the S-wave velocity distribution in the subsurface to be recovered from dispersion and numerical inversion of Rayleigh wave seismic data produced by

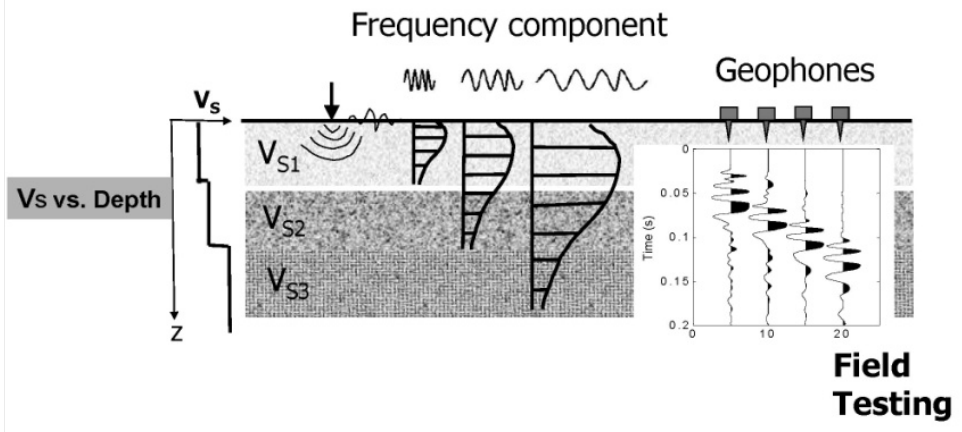

Figure 3: $\quad$ MASW data analysis. 
surface impact sources and recorded on standard digital seismographs. Figure 3 shows a schematic of the data analysis for a multi-layered profile.

The MASW testing applied at the trial site used a specially designed array to provide high resolution in the upper $1.5 \mathrm{~m}$. A 48 geophone array attached to a land streamer was towed along each line by a 4WD vehicle. At each test site the overall length of the MASW seismic spread was $26.6 \mathrm{~m}$ to extend the effective depth of investigation to the natural ground below the fill.

Two separate MASW tests were carried out at $4 \mathrm{~m}$ intervals along each line, respectively generating and detecting both high and low frequency surface waves with impact sources of different weights and offsets from the towed detector array. This approach provides both high resolution in the near surface and sufficient depth of investigation to provide the required information on the entire fill section. The high frequency data was acquired using $100 \mathrm{~Hz}$ geophones at $0.15 \mathrm{~m}$ spacing to record the higher frequency seismic signals closer to the source. $4.5 \mathrm{~Hz}$ geophones spaced at $1 \mathrm{~m}$ intervals were used to record the lower frequency data.

\section{Results and assessment}

\subsection{Cone penetrometer test results}

Comparison of the pre and post compaction CPT results generally indicated limited increase in the tip resistance and a distinctive increase in the skin friction pre and post-compaction. Some localised "peaks" occurred in the CPT results,

Table 1: $\quad$ Summary of CPT results.

\begin{tabular}{|c|c|c|}
\hline \multirow{3}{*}{ Impact Roller Weight } & Trial Area / No of Passes & $\begin{array}{c}\text { Average Depth of } \\
\text { Influence }\end{array}$ \\
\hline \multirow{2}{*}{8 tonne } & Area $1-10$ passes & $1.4 \mathrm{~m}$ \\
\cline { 2 - 3 } & Area $2-20$ passes & No Change - See Text \\
\cline { 2 - 3 } & Area $3-30$ passes & $1.8 \mathrm{~m}$ \\
\cline { 2 - 3 } & Area $4-40$ passes & $2.0 \mathrm{~m}$ \\
\hline \multirow{2}{*}{12 tonne } & Area $5-10$ passes & $1.3 \mathrm{~m}$ \\
\cline { 2 - 3 } & Area $6-20$ passes & $1.5 \mathrm{~m}$ \\
\cline { 2 - 3 } & Area $7-30$ passes & $1.4 \mathrm{~m}$ \\
\cline { 2 - 3 } & Area $8-40$ passes & $1.6 \mathrm{~m}$ \\
\hline
\end{tabular}


mainly for the tip resistance, and these are possibly the result of the cone encountering gravels or cobbles within the fill.

Table 1 presents a summary of the indicative depth of influence of compaction based on an analysis of the CPT results, using the change in skin friction. It should be noted that the CPT results for the area compacted with an 8 -tonne roller and 20 passes typically indicate that there is limited change in the tip resistance and skin friction between the pre-compaction to the postcompaction results. This does not necessarily indicate that the compaction process is not effective but rather probably indicates that the fill within this area was relatively dense prior to the commencement of the trial.

\subsection{Density test results}

A comparison of the density test results in each area generally indicates an increase the depth of influence with increasing number of blows, and a generally consistent average improvement in the density ratio within the depth of influence.

Table 2 presents the results of the density testing in terms of depth of influence and the average DDR within the compacted zone.

It should be noted that in the area compacted using a 12-tonne roller and 40 passes, the initial density of the material was significantly higher than other areas of the trial site, hence there was limited change in the density test results.

Table 2: $\quad$ Summary of density results.

\begin{tabular}{|c|c|c|c|}
\hline $\begin{array}{c}\text { Impact } \\
\text { Roller } \\
\text { Weight }\end{array}$ & $\begin{array}{c}\text { Trial Area / No of } \\
\text { Passes }\end{array}$ & $\begin{array}{c}\text { Average Depth of } \\
\text { Influence }\end{array}$ & $\begin{array}{c}\text { Average DDR in } \\
\text { Compacted Zone }\end{array}$ \\
\hline \multirow{4}{*}{8 tonne } & Area $1-10$ passes & $1.05 \mathrm{~m}$ & $99 \%$ \\
\cline { 2 - 4 } & Area $2-20$ passes & $1.35 \mathrm{~m}$ & $99 \%$ \\
\cline { 2 - 4 } & Area $3-30$ passes & $1.65 \mathrm{~m}$ & $100 \%$ \\
\cline { 2 - 4 } & Area $4-40$ passes & $1.95 \mathrm{~m}$ & $99 \%$ \\
\hline \multirow{3}{*}{12 tonne } & Area $5-10$ passes & $1.35 \mathrm{~m}$ & $96 \%$ \\
\cline { 2 - 5 } & Area $6-20$ passes & $1.65 \mathrm{~m}$ & $100 \%$ \\
\cline { 2 - 5 } & Area $7-30$ passes & $2.35 \mathrm{~m}$ & $100 \%$ \\
\cline { 2 - 5 } & Area $8-40$ passes & $1.95 \mathrm{~m}$ & $100 \%$ \\
\hline
\end{tabular}

Comparison of the density tests between the areas compacted with the different rollers generally indicates that, except for the areas compacted with 10 
passes, the post-compaction DDR was slightly higher in the compacted in an area compacted with a 12-tonne roller than an area compacted with 8-tonne roller, for a given number of passes. Also, the depth of influence of the compactors was deeper for the 12-tonne roller compared to the 8-tonne roller.

\subsection{MASW results}

The basic premise for the assessment of the MASW results is that the higher the S-wave velocity, the higher dynamic stiffness and hence the density of the fill. The MASW test results are presented as high frequency data and low frequency data S-wave velocity sections.

The high frequency data allows more detail to be obtained and finer contouring of the S-wave distribution but is limited to the upper $1.5 \mathrm{~m}$ depth. The low frequency data allows coarser contouring of the shear wave distribution but extends to depths of up to $6 \mathrm{~m}$.
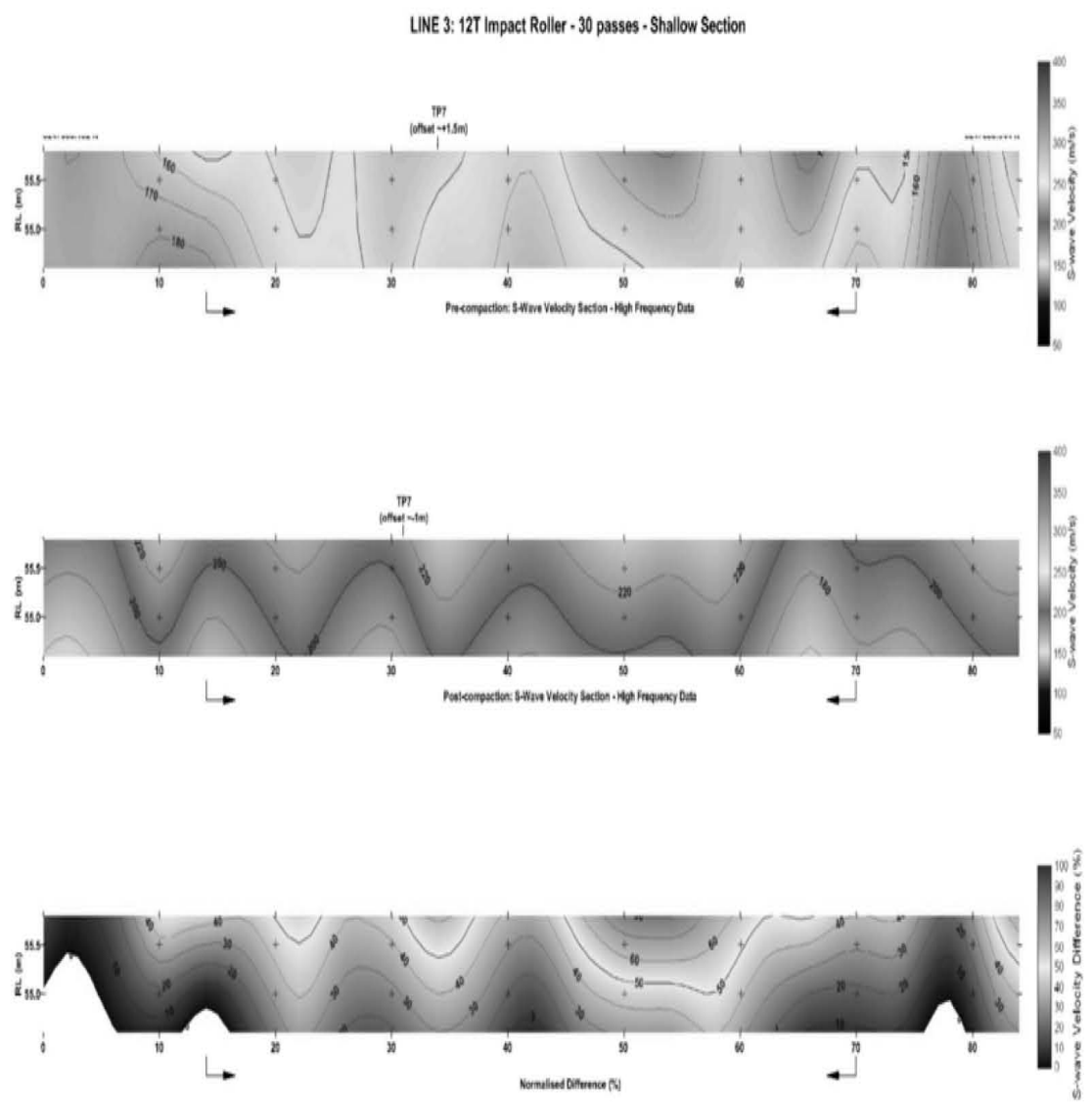

Figure 4: $\quad$ S-wave profile - shallow section. 
The results of the MASW testing are presented as S-wave velocity sections beneath the centre of each test line. For each section, three plots are obtained, namely the pre-Compaction S-Wave Velocity, the Post-Compaction S-Wave Velocity and the normalised percentage change in S-wave Velocity between the pre- and post-compaction MASW tests. Figures 4 and 5 show the MASW results for one line before and after 30 passes of the 12 tonne impact roller.

The pre-compaction S-wave velocity distribution obtained generally showed that there is a significant amount of variability both with depth and across the site. The post-compaction shear wave velocities generally indicate that there is a degree of consistency, in terms of magnitude and distribution of velocities along the test lines.
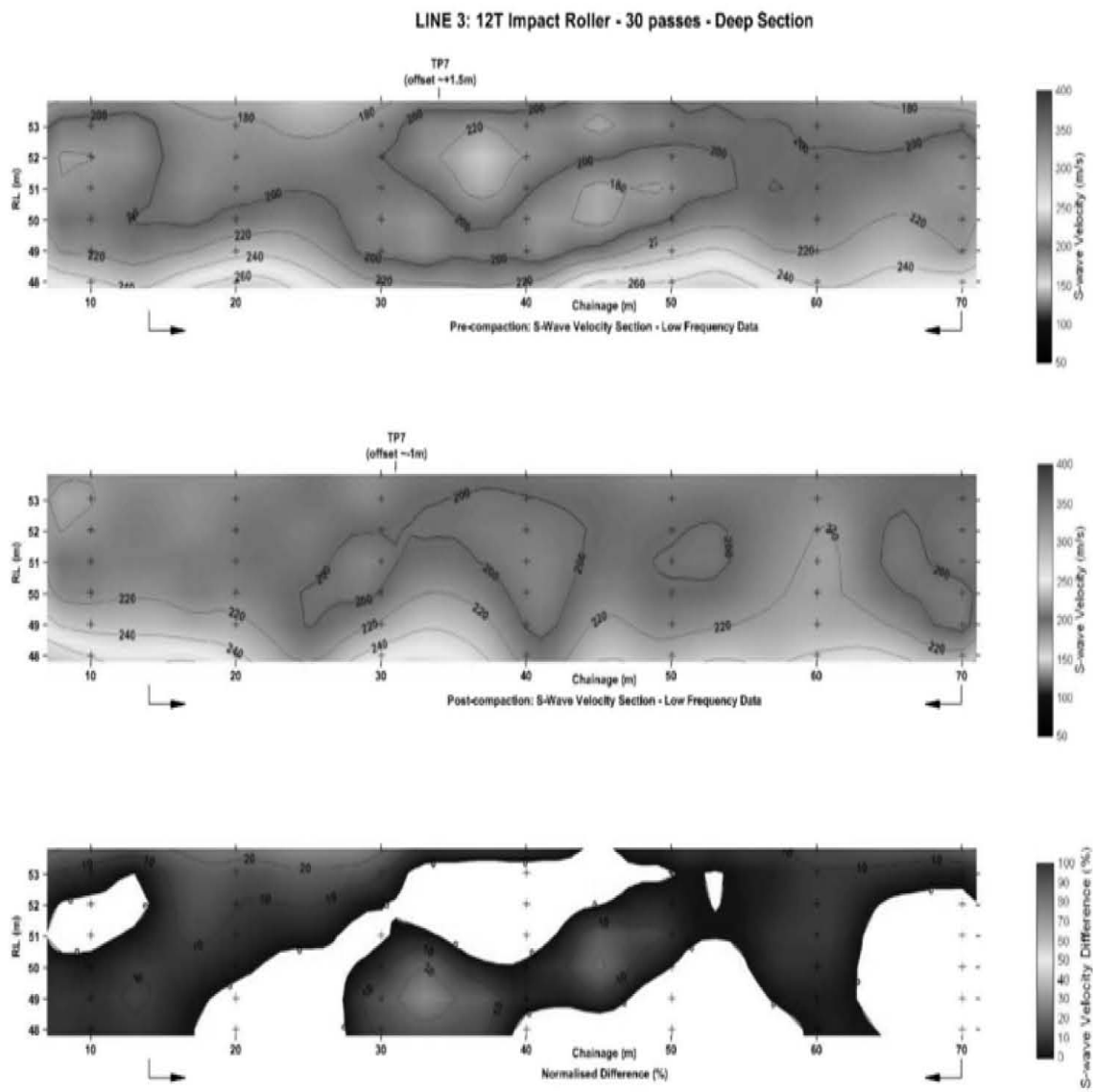

Figure 5: $\quad$ S-wave profile - deeper section.

Comparison of the post-compaction S-wave velocities across the trial site after each round of passes also generally showed a corresponding increase in Swave velocity with the number of passes of the impact roller. Comparison of the 
post-compaction shear wave velocities in areas compacted with the 8-tonne and 12-tonne roller generally show higher $\mathrm{S}$-wave velocities in areas compacted with the 12-tonne roller. However, after 40 passes the post-compaction shear wave velocities in areas compacted by the 12-tonne roller are similar to the shear wave velocities in the area compacted after 40 passes by the 8 -tonne roller.

Figures 6 shows plots of S-wave velocity near the test pit locations versus density (in $\mathrm{t} / \mathrm{m}^{3}$ ) and Dry Density Ratio (DDR) determined at the test pit locations for both the pre- and post-compaction. These show a distinctive increase in both the density (in $\mathrm{t} / \mathrm{m}^{3}$ and DDR) and shear wave velocity as a result of the impact compaction.

The data presented in Figure 6 has relatively high standard deviation probably due to the heterogeneous nature of the fill. A lower quartile trend line for the relationship between S-Wave velocity and DDR was developed for the postcompaction data to develop verification criteria. Based on this line, where an Swave velocity of at least $200 \mathrm{~m} / \mathrm{s}$ is achieved, at least $75 \%$ of the test data has a DDR greater than $98 \%$ of the SMDD.

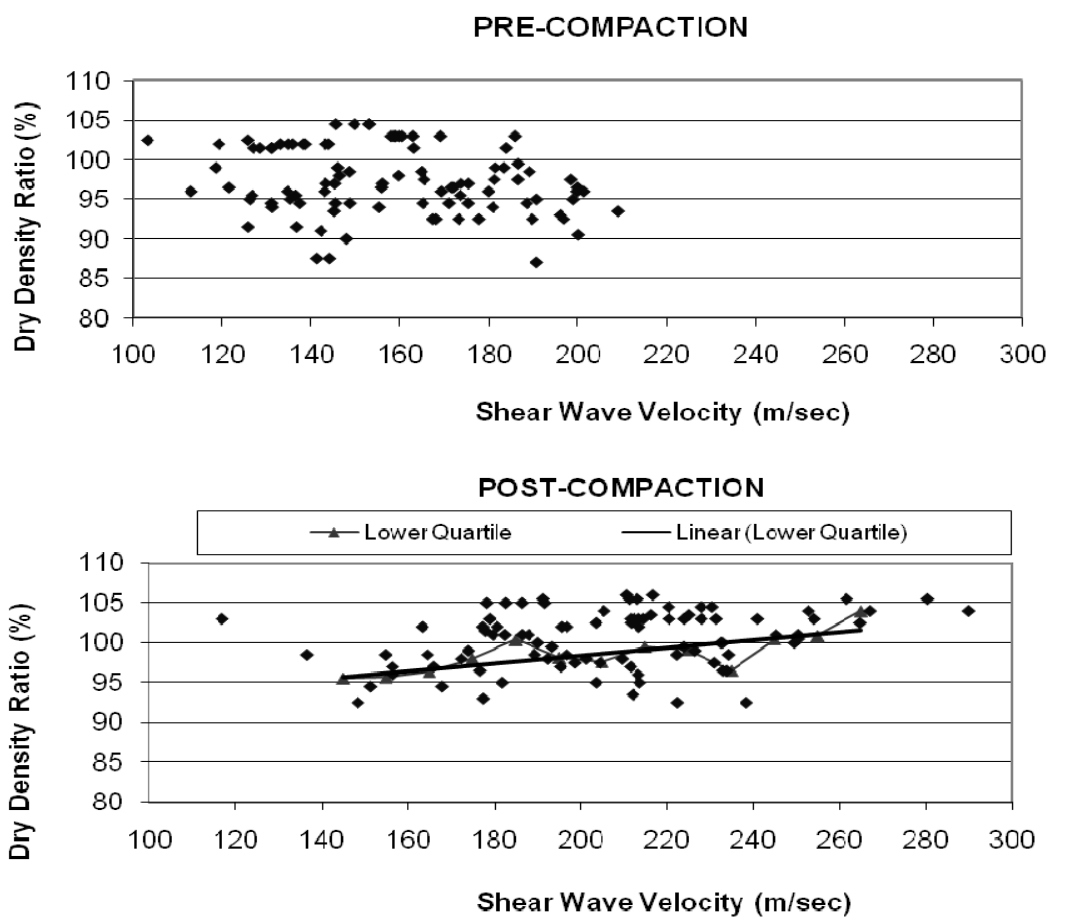

Figure 6: Density versus S-wave velocity. 


\subsection{Dynamic cone penetrometer test results}

Comparison between the pre- and post-compaction DCP test results indicates that there is highly variable increase in the blow count per $50 \mathrm{~mm}$ to depths in excess of $3 \mathrm{~m}$. The increase varies between 1 and 15 blows per $50 \mathrm{~mm}$.

\subsection{Summary of results}

Figure 7 shows a comparison of CPT cone and sleeve friction values, field density test results, S-wave velocity and DCP results pre- and post-compaction

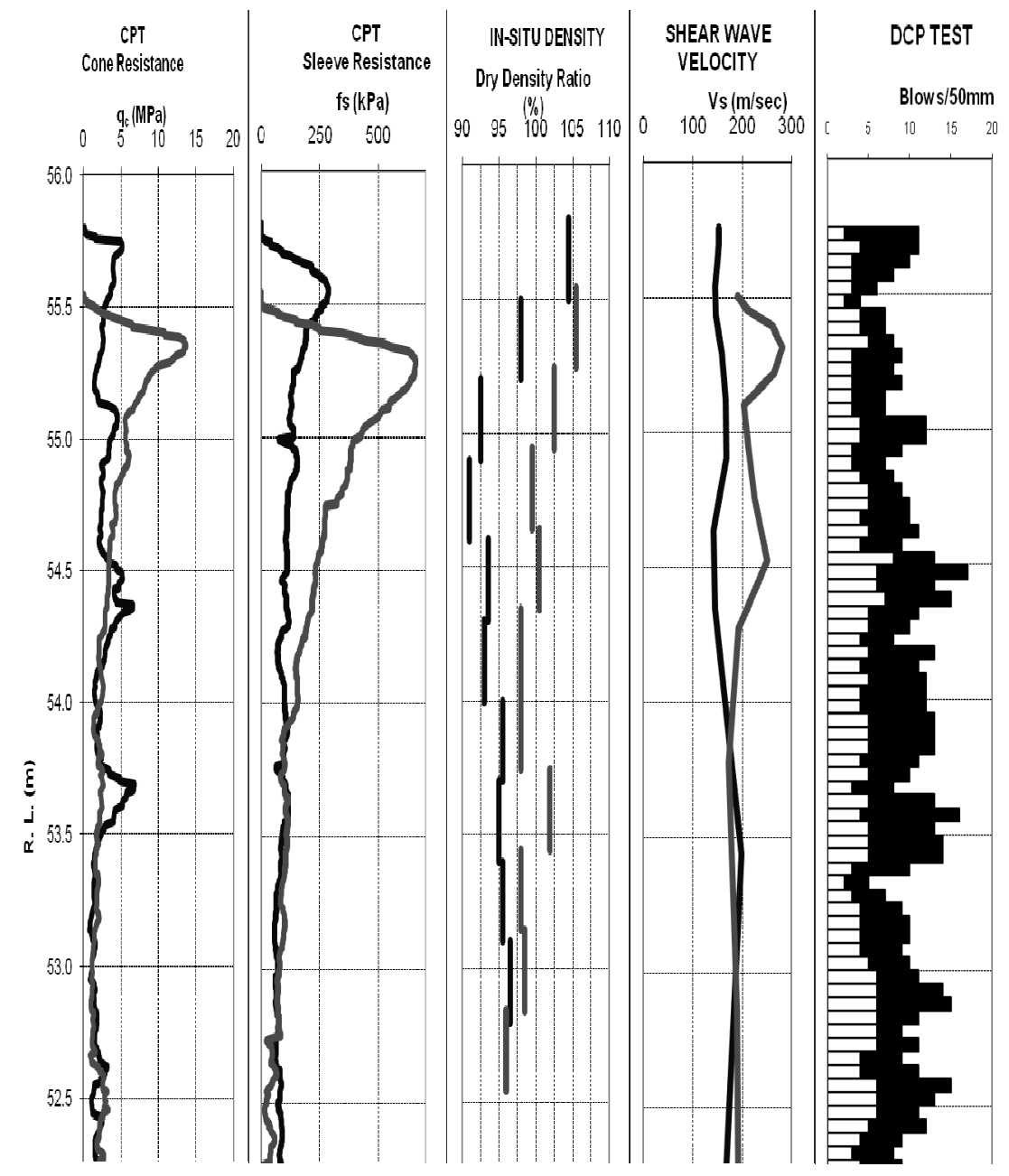

Figure 7: Comparison of pre and post compaction CPT, density, shear velocity and DCP results for 20 passes of a 12 tonne roller. 
for the trial area where 20 passes was undertaken using a 12 tonne impact roller. Figure 7 illustrates the relatively good correlation between CPT sleeve friction, density tests and S- wave velocity. This was the case across the trial area.

\subsection{Topographic survey}

Accurate survey of the prepared ground surface was taken prior to the commencement of the impact compaction to establish a baseline surface profile and then after every 5 passes with the roller. The topographic survey results provide an assessment of the "global" response of the ground to the impact rolling after every 5 passes.

Figure 8 shows the surveyed average settlement monitored resulting from the 8 tonne and 12 tonne impact roller.

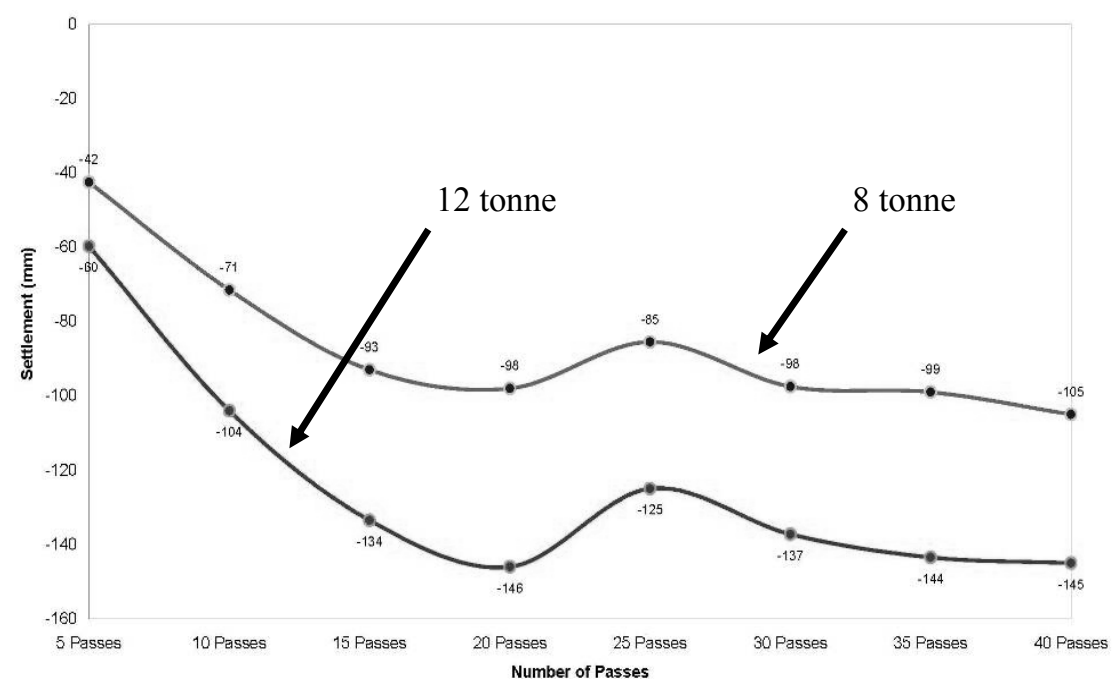

Figure 8: $\quad$ Mean settlement of compacted area.

The topographic survey results indicate the following:

- The shape of the fitted curve through the survey points presenting settlement versus number of passes is consistent throughout the trial areas, with the rate of settlement being initially high and then reducing with increasing number of passes.

- In areas compacted with more than 20 passes, there is an apparent heave of the ground surface after 25 passes. This appears to be due to ground disturbance after compaction and before the survey of the areas after 25 blows.

- After 20 passes with the roller, the majority of the total settlement recorded has been substantially achieved. For example, in areas compacted using the 8 tonne roller $93 \mathrm{~mm}$ of settlement was recorded after the first 20 passes, with only an additional $8 \mathrm{~mm}$ settlement from a subsequent 20 passes. 


\section{Summary and conclusions}

The extensive geotechnical and geophysical test results from trial area containing uncontrolled fill indicates reasonable correlation between the CPT, density and S-wave velocity. All show a similar depth of influence as a result of impact compaction. The depth of influence generally increases with increasing number of machine passes, albeit by only a relatively small amount.

DCP results after compaction gave blow counts between 1 and 15 times those recorded at similar locations for pre-compaction tests and are considered to be an unreliable indicator of density due to the gravel and cobble content in the fill. In comparison, the in situ density test results increased by $6 \%$ to $10 \%$ and S-wave velocities increased by up to $40 \%$.

Based on the results of the extensive geotechnical and geophysical testing completed in the trial it was concluded that:

- The MASW testing provided shear wave velocity profiles showing the consistency achieved in the landform. The results indicate both high and low frequency data is required, using the high frequency data to assess the densification of the shallow fill and the coarser, low frequency data to assess the fill to greater depth.

- A statistical approach was used to develop a relationship between the MASW testing and DDR. From this relationship a target shear wave velocity of at least $200 \mathrm{~m} / \mathrm{sec}$ in the upper $1.5 \mathrm{~m}$ depth of fill and at least $180 \mathrm{~m} / \mathrm{sec}$ to a depth of $1.5 \mathrm{~m}$ was developed for this site.

- There was reasonable correlation between the CPT, density and S-wave velocity. All show a similar depth of influence as a result of impact compaction. The depth of influence generally increases with increasing number of impact roller passes, albeit by only a relatively small amount.

- CPTs were the only geotechnical testing method trialed that provided a clear indication of the depth of influence of the impact rolling.

- Field density testing was the only test method that provided a direct assessment of DDR. Stronger relationships would need to be developed between the density and other testing methods to negate the need for direct density testing.

- $\quad$ DCP results are an unreliable indicator of density at the site due to the gravel and cobble content in the fill.

- The topographic survey provided an indication of the overall response of the landform to impact rolling and can be used to assist in assessing the required number of passes.

- By applying at least 25 passes of a 12-tonne impact roller it is possible to achieve the project geotechnical criteria of at least $98 \%$ of the SMDD in the upper $1.5 \mathrm{~m}$ of fill.

The above conclusions were used as a basis for the development of a geotechnical verification strategy for the site. 


\section{References}

The following papers provide additional reference for investigations using MASW and the effects of impact compaction.

[1] Avalle, D (2007), Ground Vibrations During Impact Rolling, Common Ground Proceeding, 10th Australia New Zealand Conference on Geomechanics, Brisbane.

[2] Bouazza A., Avalle D L (2006); Effectiveness of Rolling Dynamic Compaction on an Old Waste Tip; Conference Proceedings ISSMGE 5th International Congress on Environmental Geotechnics, Cardiff

[3] Burke, R. W., Schofield N. B. (2008) The Multichannel Analysis of Surface Waves Method As A Tool for Ground Improvement Certification, Symposium on the Application of Geophysics to Environmental and Engineering Problems, Colorado USA 